\title{
Spatial analysis of the prevalence of schistosomiasis in an endemic coastal area in north-eastern Brazil
}

\author{
Allan D. Santos, ${ }^{1,2}$ Jonhnatas Silva, ${ }^{3}$ Ana Caroline Lima, ${ }^{3}$ Márcio Santos, ${ }^{2,4}$ Shirley Lima, ${ }^{1,2}$ \\ Monalisa Amor, ${ }^{3}$ Carlos Santos, ${ }^{5}$ Arthur Vasconcelos, ${ }^{6}$ Silvio Dolabella, ${ }^{3,7}$ Karina C.G.M. Araújo ${ }^{2,3,7}$ \\ ${ }^{1}$ Department of Nursing, Federal University of Sergipe, Sergipe; ${ }^{2}$ Post-Graduate Program in Health \\ Sciences Stricto Sensu, Federal University of Sergipe, Sergipe; ${ }^{3}$ Post-Graduate Program in Parasite Biology \\ Stricto Sensu, Federal University of Sergipe, Sergipe; ${ }^{4}$ Department of Health Education, Federal University \\ of Sergipe, Sergipe; ${ }^{5}$ Department of Biology, Federal University of Sergipe, Sergipe; ${ }^{6}$ Department of \\ Medicine, Federal University of Sergipe, Sergipe; ${ }^{7}$ Department of Morphology, Federal University of \\ Sergipe, Sergipe, Brazil
}

\begin{abstract}
Due to contact and misuse of water drainage channels, schistosomiasis has spread and become a constant concern in northeastern Brazil. The aim of this study was to monitor human cases of Schistosomiasis mansoni and the breeding areas of the snail
\end{abstract}

Correspondence: Karina Conceição Gomes Machado Araújo, Research Centre in Schistosomiasis and Health Geoprocessin, NUPEGEOS, CNPq, Federal University of Sergipe, Sergipe, Brazil.

E-mail: Kkkaraujo2006@yahoo.com.br

Key words: Urban schistosomiasis; Spatial analysis; Biomphalaria; Geographical information system; Brazil.

Ethical notes: this project was approved by the Ethical Committee of the Federal University of Sergipe, Brazil, CAAE 23404113.0.0000.5546.

Acknowledgments: we thank the research funding sources: SVS/MS (Ministry of Health, Brazil), CNPq/Universal, PROEF and PROMOB/CAPES/FAPITEC-SE

Received for publication: 2 April 2017.

Revision received: 21 October 2017.

Accepted for publication: 6 November 2017

Conflict of interest: the authors declare no potential conflict of interest.

Contributions: the authors contributed equally.

Funding: PPSUS/FAPITEC/SE/SES N ${ }^{\circ}$ 02/2013, PIBIC/CNPq granted regular assistance to the research.

(C) Copyright A.D. Santos et al., 2017

Licensee PAGEPress, Italy

Geospatial Health 2017; 12:570

doi:10.4081/gh.2017.570

This article is distributed under the terms of the Creative Commons Attribution Noncommercial License (CC BY-NC 4.0) which permits any noncommercial use, distribution, and reproduction in any medium, provided the original author(s) and source are credited. intermediate host Biomphalaria glabrata through spatial analysis in a community named Invasão do Canal do Guaxinim, located in Barra dos Coqueiros City in an endemic coastal part of the state of Sergipe, Brazil. This research was performed as a cross-sectional epidemiological study conducted with parasitological and malacological surveys. To verify the spatial analysis, a two-year spatial point pattern analysis was performed by means of Kernel intensity estimation using TerraView software 4.2.2. A schistosomiasis prevalence reduction from $8.1 \%$ (2013) to $4.9 \%$ (2014) was observed but mild infection prevailed in adolescents and/or young adults during the two-year study. In malacological research, 387 specimens of snails of the genus $B$. glabrata were collected and all were negative with regard to schistosomiasis. Spatial analysis showed a strong, spatial trend of increased transmission risk areas north and south of the community, both in 2013 and 2014. In Invasão do Canal do Guaxinim itself, the increased risk was only seen in the northern part. When combined, the human and the malacological spatial analyses constituted an important methodological approach for monitoring and controlling this parasitic disease.

\section{Introduction}

Schistosomiasis is a serious parasitic disease prevalent in tropical and subtropical regions, especially in communities with inadequate water supplies and sanitation (Chitsulo et al., 2000; Hotez et al., 2010). The disease occurs in 78 countries in Latin America, Asia and Africa, the latter of which is responsible for $85 \%$ of cases. In 2013, the World Health Organization (WHO) estimated that 249 million people need treatment for schistosomiasis, while the actual number of people treated in 2012 was only 42.1 million (WHO, 2014).

In Brazil, the disease is caused by Schistosoma mansoni, and some data indicate that it affects approximately eight million people with approximately 30 million are at risk (Brazilian Ministry of Healthy, 2013; Sarvel et al., 2011). Schistosomiasis occurs in 18 states, including the Federal District and is particularly prevalent in the Northeast, Southeast and Midwest. In the Northeast, Biomphalaria straminea and B. glabrata are the snail intermediate host species responsible for its transmission (Barbosa et al., 2014).

Expansion of schistosomiasis to touristic localities has been observed in several places in Brazil. The frequency of reports of 
urban schistosomiasis cases has been increasing, with transmission patterns observed and recorded in several localities where tourist developments have been stimulated without proper structural support and without environmental regulation and inspection (Enk et al., 2010; Massara et al., 2008). In Sergipe, schistosomiasis has a wide distribution in both rural and urban areas (Rollemberg et al., 2011; Santos et al., 2016). Data from the Schistosomiasis Control Program (DATASUS, 2015) show that this situation is also seen in Barra dos Coqueiros City, the metropolitan area of the capital, mainly because it has a flat relief which favours the formation of temporary or permanent water basins that can act as snail breeding sites. These geographic characteristics, coupled with poor sanitation conditions and lack of health education, favour the initiation and maintenance of the transmission cycle in these areas. This city has a water drainage channel for excess rainfall along the community of Guaxinin Creek, referred to as Invasão do Canal do Guaxinin which is located in the central urban area in the endemic coastal area, where it offers multiple opportunities for $S$. mansoni infection.

Geographic information systems (GIS) have been used worldwide in various studies for disease monitoring through computational resources providing spatial analysis of information in a geographic context. In some studies of schistosomiasis, it has become feasible to incorporate epidemiological information using GIS tools and these studies have contributed towards an understanding of the spatial distribution and expansion of intermediate host snails in different endemic areas as well as the spatial dynamics of schistosomiasis transmission including its temporal interactions. This has led to a more efficient control of the infection and improved the understanding of transmission dynamics (Yang et al., 2005; Clennon et al., 2007; Barbosa et al., 2011, 2014; Scholte et al., 2012, 2014).

The epidemiological relevance of schistosomiasis in northeastern Brazil, made us investigate the occurrence of schistosomiasis in Invasão do Canal do Guaxinim. In this study, our research group sought to evaluate the local prevalence of schistosomiasis through spatial analysis because this place has been a favourable setting for maintaining the biological cycle of $S$. mansoni for decades. We describe here the prevalence and intensity of $S$. mansoni infection as well as the occurrence and spatial distribution of the breeding sites of the snail intermediate hosts.

\section{Materials and Methods}

\section{Study design}

An epidemiological cross-sectional study was conducted to compare the prevalence of $S$. mansoni infection between the years 2013 and 2014; geoprocessing techniques were used and both parasitological and malacological surveys were conducted. Invasão do Canal do Guaxinim was chosen because it is an urban area on the banks of Guaxinim Creek, which is endemic for schistosomiasis. The community belongs to the Sergipe River Basin, where water is channelled to assist in big rainfall runoffs from a housing development built in the early 1990s.

\section{Study area and climate}

The study was conducted in Barra dos Coqueiros City, located $3 \mathrm{~km}$ from Aracaju, the state capital of Sergipe, Brazil (Figure 1).
The city is located on Santa Luzia Península on the banks of the Sergipe River. According to the Brazilian Institute of Geography and Statistic (IBGE) the geographic coordinates are $10^{\circ} 54$ '41"South and $37^{\circ} 1$ '47" (IBGE, 2015). The climate of Barra dos Coqueiros is hot and humid to sub-humid with an average temperature of $26^{\circ} \mathrm{C}$ and the annual rainfall amounts to about 1,560 $\mathrm{mm}$. The rainy season is from March to August.

According to data from the Primary Care Information System, Invasão do Canal do Guaxinim comprised 239 households with a total population of 877 inhabitants, 52.3\% female, in 2012 (Brazilian Ministry of Healthy, 2013). All households have access to safe drinking water, although intermittently, which leads people to often use the channel drainage water for daily activities. Only $41 \%$ of the households are served by public garbage collection and only $1 \%$ of the population has full access to sanitary conditions. Even if this means that the channel receives sewage waste, local people use water from it for household activities. In addition, it is infested with Biomphalaria sp. snails. The combination of contamination of surface water with open sewers and snail presence are important determinants for the presence of schistosomiasis transmission.

\section{Parasitological survey}

The surveys were conducted at the end of August in both years (2013 and 2014); randomly selected households were visited by researchers and agents working for the Program of Control of Schistosomiasis (PCE) distributing and collecting containers for stool tests. However, we had some problems applying the second questionnaire (in 2014) as we could not access all people approached in 2013.The researchers considered the same households but due high people mobility some individuals had moved out and were thus not included in the second survey. This limitation was expected as people change address frequently in this area. However, we felt that it would be possible to evaluate the infection circumstances by evaluating the prevalence at the population level. The minimum annual sample size required to obtain results with statistical significance was conducted using the Barbetta formula (2002) aiming for a maximum error of 5\% for schistosomiasis in the community based on the number of inhabitants. It was established that a minimum number of 268 inhabitants were required for a confidence level of $95 \%$.

The parasitological material was prepared and shipped to a laboratory belonging to the County Health Department. The parasitological diagnosis was conducted by stool examination (Katz et al., 1972) using two slides per sample. The rate of human infection, or the individual parasitic load, was defined by multiplying the mean number of eggs found on the two slides by a constant $(=24)$, which gives the number of eggs per gram (epg) of faeces as described by Katz et al. (1972). Based on this survey, the following rates of infection with $S$. mansoni were determined as recommended by the WHO (Brazilian Ministry of Healthy, 2013): i) prevalence: the percentage of egg-positive persons; ii) intensity of infection: the average epg number among the positive individuals; and iii) percentage of people with $>100 \mathrm{epg}$, i.e., the prevalence of moderate to severe infection.

The intensity was categorised as light $($ epg< $<99)$, moderate

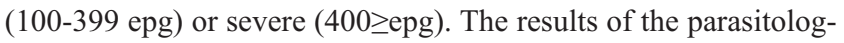
ical examinations were revealed to the study population after the survey and treatment was offered to all individuals who had tested positive for schistosomiasis. 


\section{Malacological survey}

The malacological survey was conducted in the beginning of August in 2013 and 2014 (the rainy season usually starts in May), since it was then possible to collect the snails in the water puddles along an area that measured 3 by $0.3 \mathrm{~km}$ stretching along Invasão do Canal do Guaxinim which corresponded to all accessible extensions of the basins with human contact and/or evidence of faecal contamination. After the area had been mapped with the breeding sites identified and georeferenced, the malacological survey was carried out by systematically collecting rfelevant snails (Olivier and Schneiderman, 1956) from all basins in the study area, such as wetlands, water runoff ditches and rainwater puddles in the streets. The snails were placed in labelled jars and taken to the Central Public Health Laboratory of Sergipe (LACEN-SE). The specimens were examined on the $1^{\text {st }}$ and the $30^{\text {th }}$ day after initiation of the collection scheme to check the infectivity rate, which was determined by light exposure (Souza and Lima, 1990) and to confirm the species through dissection of the genitalia (Deslandes, 1951).

\section{Spatial data processing}

The road network in the urban area of Barra dos Coqueiros City was produced with help of Google Earth. To spatially locate human cases of schistosomiasis and snails, the absolute method of Hofmann-Wellenhof et al. (1997) with instantaneous point positioning was used; the data were collected with a Garmin, model Vista $\mathrm{Cx}$ global positioning system (GPS) navigation receiver with a resolution of $2.5 \mathrm{~m}$ after correction set in the Universal Transverse Mercator (UTM) projection system, Datum SAD 69 and the reference ellipsoid. The spatial distribution was determined using TerraView software, version 4.2.2 (http://www.dpi.inpe.br/ terraview), with the analytical unit comprising households around Invasão do Canal do Guaxinin which has well-defined limits. A database was created using the GPS TrackMaker Pro software, version 13.9 complemented with an image of the central part of the city from the QuickBird satellite (http://glcf.umd.edu/data/quickbird/).

The mapping of the spatial distribution of schistosomiasis in the community was done to evaluate the geographical variation of

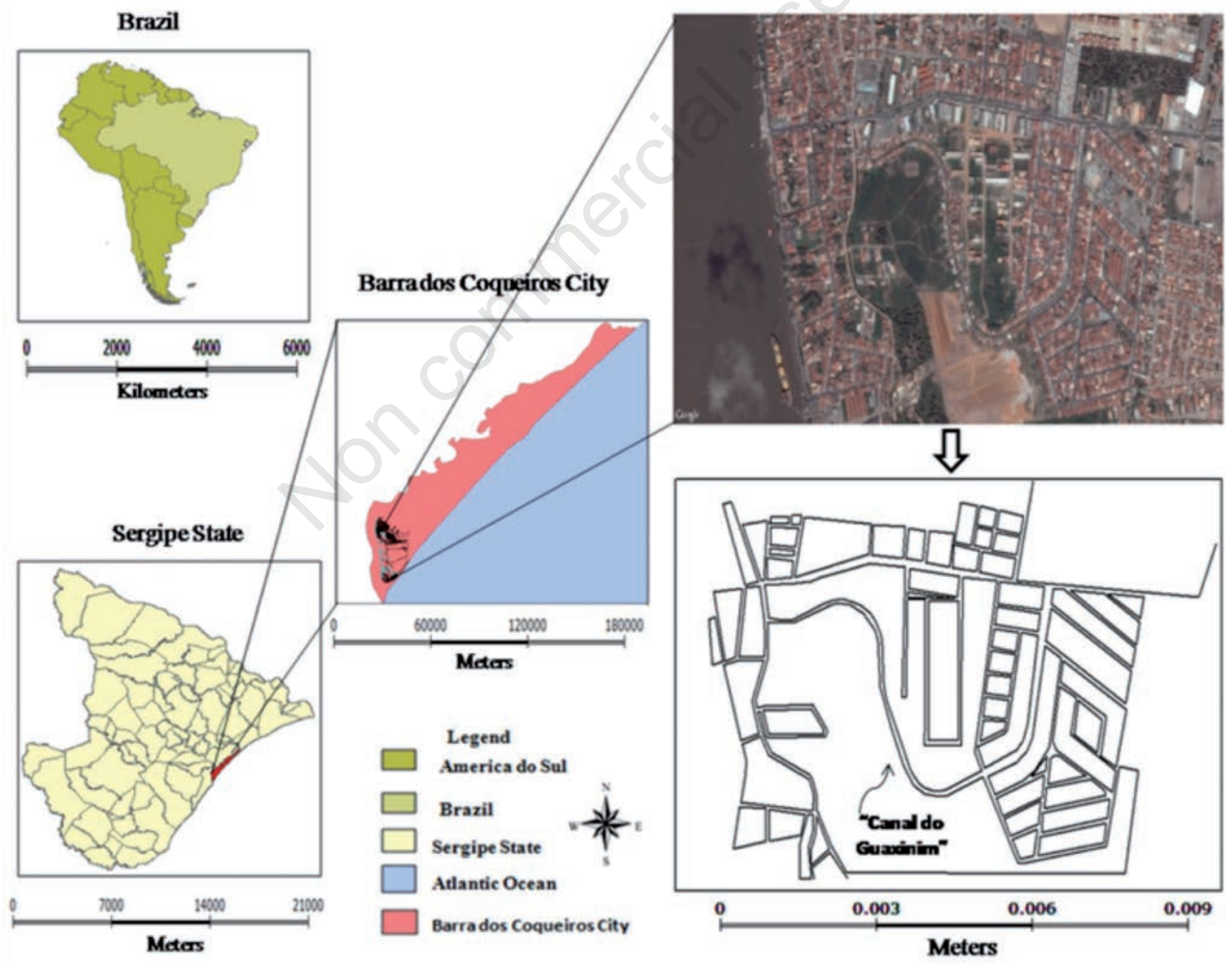

Figure 1. Maps and satellite image of the study area. 
its prevalence and to identify the distribution of potential areas of risk. The Kernel intensity estimator was used for spatial analysis, which made it possible to estimate the number of events per unit area in each cell of a regular grid covering the study area. This is a non-parametric technique that promotes smoothing or statistical softening to allow filtering the variability of datasets, while retaining the essential characteristics of the sites. By smoothing or statistical softening, this technique generates a surface density for visual detection of hotspots, defined as a concentration of events indicating agglomeration in a spatial distribution and a continuous surface from the data points (Cromley et al., 2002). The smoothness was controlled by choosing a bandwidth indicating the area to be considered in the calculation that should reflect the geographical scale of the hypothesis of interest as well as prior knowledge of the event studied.

\section{Statistical analysis of descriptive data}

A database of the epidemiological data was created using Microsoft Excel software, version 2010. To evaluate the strength of the association between the variables, a descriptive statistical analysis was performed by the chi-square test. The level of signif- icance was set at $5 \%(\mathrm{P}<0.05)$. All statistical analyses were performed using BioEstat software, version 5.0.

\section{Results}

In 2013, we conducted 272 parasitological diagnostic faeces tests in individuals aged 1-78 years, finding 22 positive for $S$. mansoni. The prevalence of infection in 2013 was $8.1 \%$, and the geometric mean was 103.6 epg faeces. Among the positive individuals, $16(72.8 \%)$ had a mild infection, five $(22.7 \%)$ a moderate infection and one $(4.5 \%)$ a severe infection. In the survey conducted in 2014, 267 samples were examined in individuals 3-74 years of age, out of which 13 were considered positive. The prevalence of $S$. mansoni infection in 2014 was $4.9 \%$, and the geometric mean was $483.7 \mathrm{epg}$ of faeces. Among the positive individuals, eight $(61.5 \%)$ had a mild infection, two (15.4\%) a moderate infection and three $(23.1 \%)$ a severe infection. There was thus a prevalence reduction of $39.9 \%$.

In $2013,54.6 \%$ of the infected individuals were male subjects.

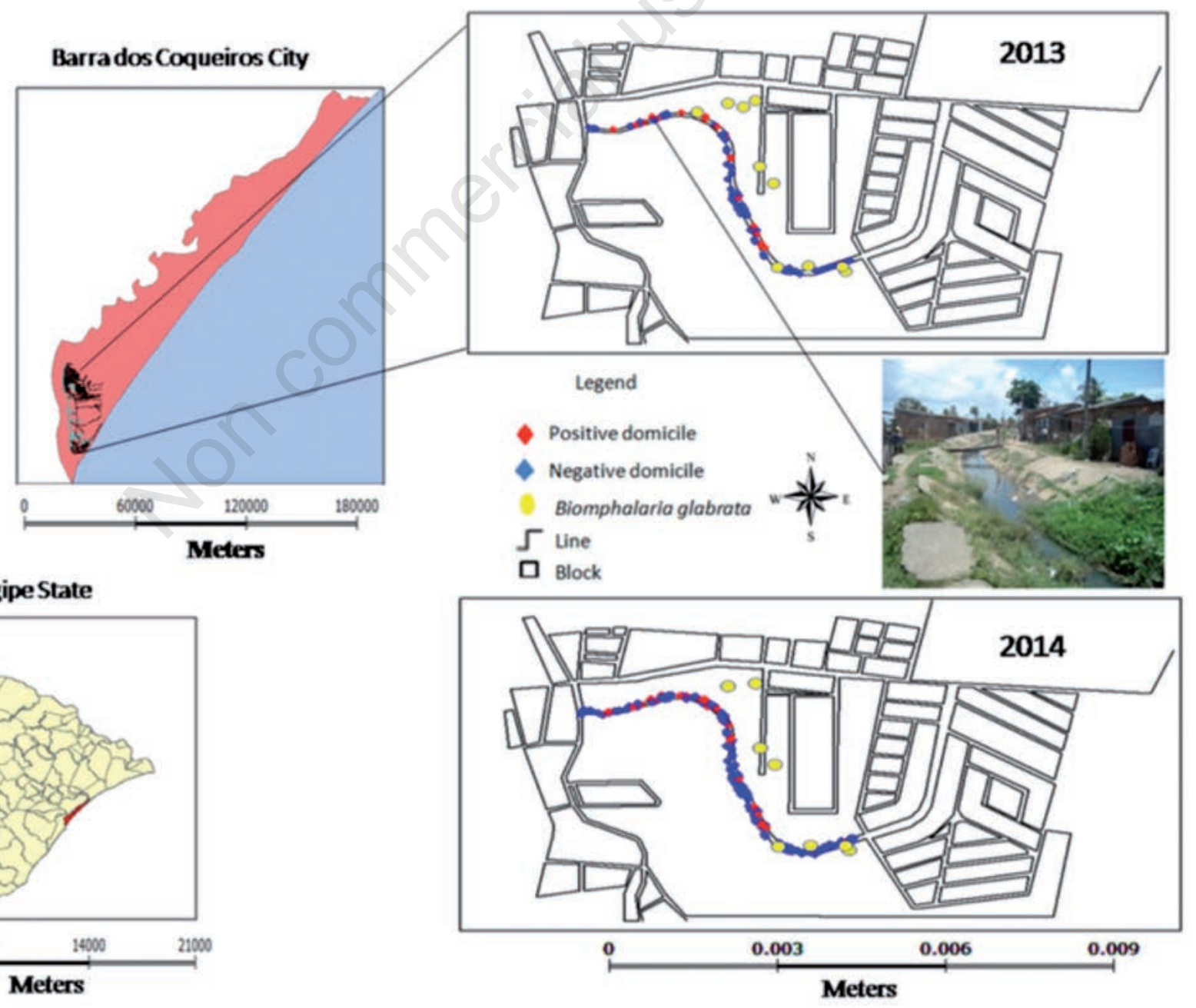

Figure 2. The spatial distribution of Biomphalaria glabrata breeding sites and households in Invasão do Canal do Guaxinim, Brazil. 
An analysis of the frequency of schistosomiasis cases by age revealed that $41 \%$ of the cases were teenagers (10-19 years old), $36.3 \%$ were young adults (20-39 years old) and $22.7 \%$ were adults (40-59 years old). There were no positive results for S. mansoni in children ( $0-9$ years) or in the elderly ( $>60$ years). The chi-square test $\left(X^{2}=-53.0450\right)$ showed a significant difference in the distribution of cases in terms of age $(\mathrm{P}<0.0001)$. The mean age was 26.5 years.

In $2014,62 \%$ of the affected subjects were women. Women aged 20-39 years were the most affected (30.7\%) followed by adolescents aged 10-19 years (23.4\%). Adults (40-59 years), children ( $0-9$ years) and elderly ( $>60$ years) each represented $15.3 \%$ of the infected population. The chi-square test $\left(\mathrm{X}^{2}=-53.0450\right)$ showed a significant difference in the distribution of cases in terms of age $(\mathrm{P}<0.0001)$. The mean age was 29.8 years \pm 0.45 .

In the malacological investigation 10 B. glabrata breeding sites, the only snail intermediate host along Invasão do Canal do Guaxinim and its vicinity in 2013, were identified and mapped. In the survey conducted in 2014, only eight breeding sites for this snail species were detected Figure 2 shows the geographical coordinates observed within the channel and in nearby areas.

The current two-year study area had the same environmental and health conditions observed in previous years: unpaved streets, homes with wastewater disposal and sewage discharged directly into the channel, which was infested with the snail intermediate host (Figure 3). A total of 387 snails were collected in the peridomestic collection referred to above. The number of snails collected varied from each of the identified breeding sites. All snails were considered negative for cercariae in tests after exposed to light for 30 days.

The spatial snail distribution obtained through the kernel investigation showed transmission along the whole channel. However, the test results indicated the existence of two main areas of risk in 2013: one with high intensity in the north and a second less active south of the channel. In 2014, there was only a single risk area north of the channel. It should be emphasized that although the map shows a distinct spatial pattern between the two years, as represented by varying densities of collected snails, the entire channel carried the potential transmission risk (Figure 4).

The kernel intensity estimator identified two clusters of human cases in 2013, north and south of the channel. In 2014, there was a greater concentration of cases located north of the channel. Despite differences with respect to the location of the concentration of cases each year, almost all areas had human schistosomiasis cases indicating the existence of a risk corridor throughout the entire water drainage channel (Figure 5).

By relating the spatial distribution of human cases to the presence of $S$. mansoni vector breeding sites, we observed an overlap of the areas with high intensity of human cases and the snail breeding sites north of the channel. During the two years under study, the northern area had the highest risk of transmission shown by the existence of the highest concentrations of human cases as well as B. glabrata breeding sites.

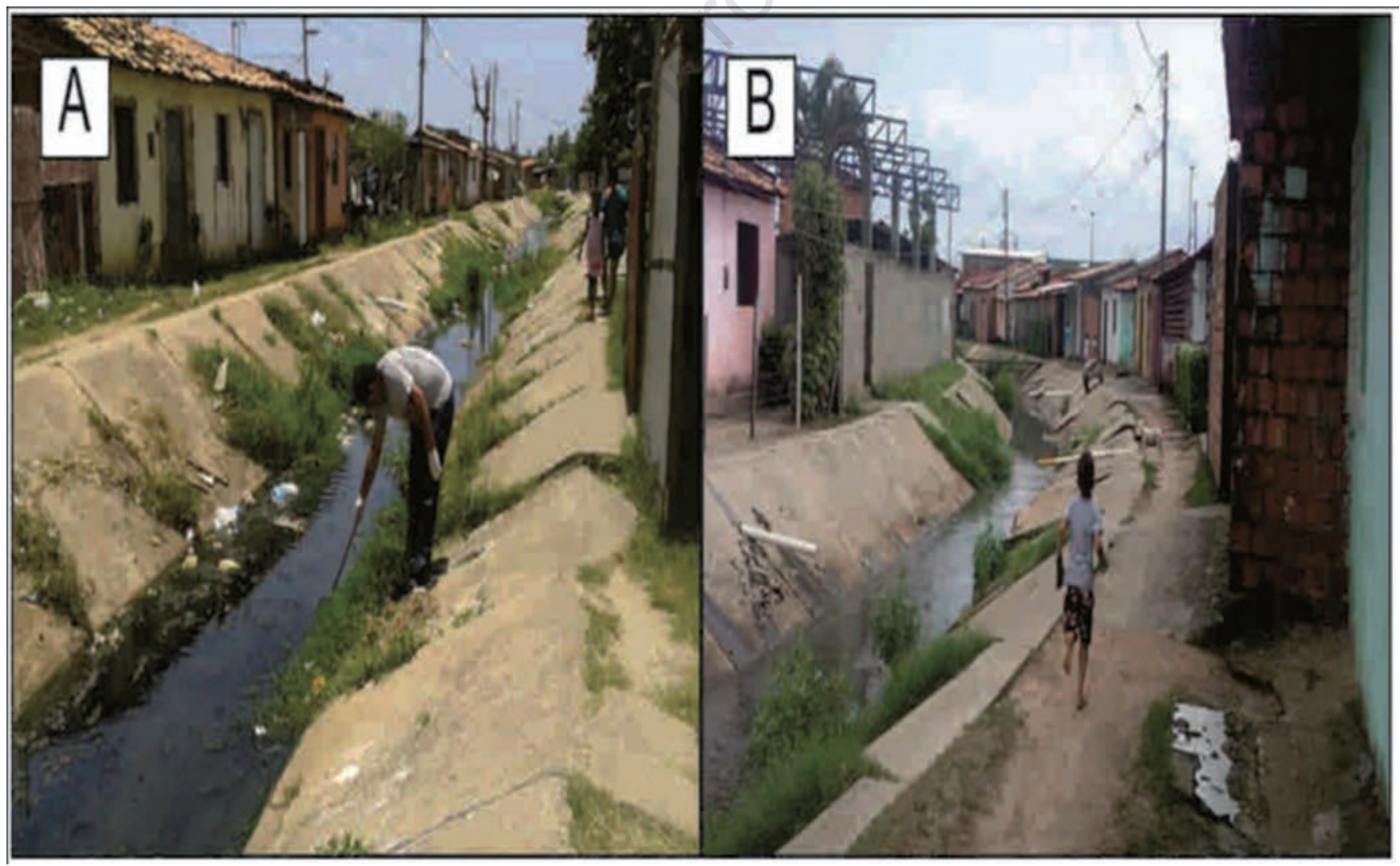

Figure 3. A) Snail collection in Canal do Guaxinim, Brazil. B) The use of channel areas for recreational activities together with open waste disposal pipes. 


\section{Discussion}

Spatial approaches to monitoring risk areas in epidemiology contribute to the understanding of which variables are associated with schistosomiasis risk, while geostatistical, social, economic, bioecological and sanitary factors emphasize the importance of human behaviour with regard to this parasite infection (Clennon et al., 2007; Yang et al., 2005). Several factors may be involved in Invasão do Canal do Guaxinim and this eco-epidemiological study collected malacological and parasitological data in the area. Spatial analysis re-evaluated these data, generating new information and allowing re-interpretation of events, confirming the importance of applying methods based on GIS in healthcare (Carvalho et al., 2005).

Regarding the age distribution of infected cases, the prevalence of the disease was higher in young people and adults, whereas the prevalence in older individuals 50 years and older was lower. The same was observed in relation to the parasite load. These values reflect that the younger age groups are more affected by schistosomiasis as they are more prone to association with $S$. mansoni risk factors, such as the use of recreational areas (in this case, run-off water sources) as well as exposure during professional activities, e.g., fishing, laundry, agriculture and irrigation (Sarvel et al., 2011).

As already noted by Gryseels (1994; young males are the most affected, in our case probably because they are more exposed to the snail breeding sites in the streets and backyards as they move in these environments developing their social and professional activities. However, it was noted there was a higher incidence of $S$. mansoni infection in women in 2014, which can be explained by the need for household chores although why this so only in one of the years studied is unclear.

Mild intensity prevailed in the two years studied, which may be explained by the seasonality of transmission and the occasional contact of individuals with outbreaks during the rainy season, a time when B. glabrata breeds more actively (Barbosa et al., 2011). The influence of biotic and abiotic characteristics such as climatic, physical and chemical factors affect the survival and development of $S$. mansoni-infected snail populations. Temperature and rainfall have been pointed out by Sturrock (1993) as the most important

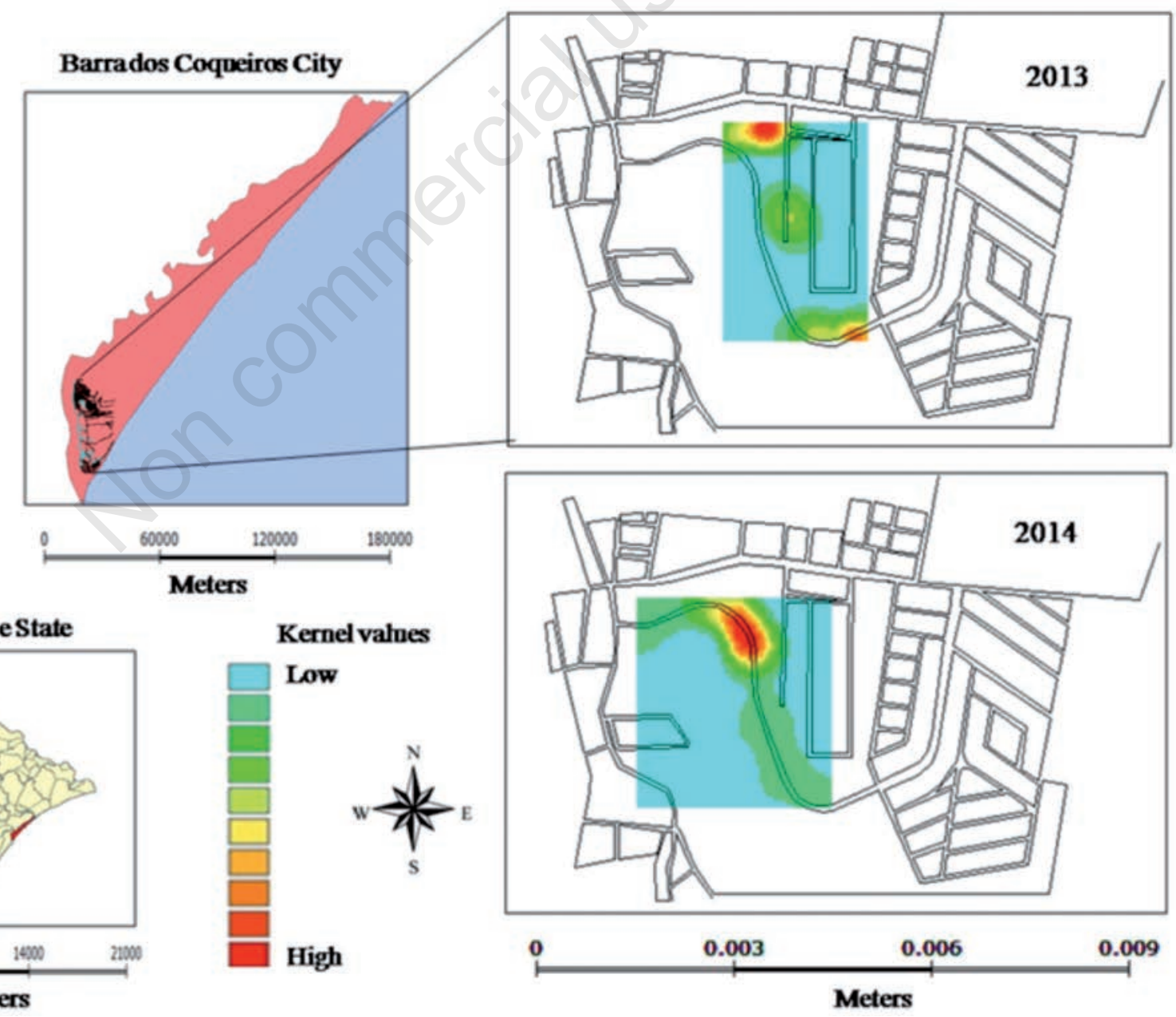

Figure 4. Kernel analysis of snail breeding sites in Invasão do Canal do Guaxinim, Brazil. 
determinants of snail population dynamics. Moreover, in the dry season no snails were found in the water collections identified during the rainy season.

In addition to the biological components, schistosomiasis has complex social and cultural aspects related to human behaviour and disorderly occupation of urban spaces (Barbosa et al., 2000, 2006). Poorly planned urban development in addition to the destruction of the original ecosystem, creates the ideal environmental conditions for the emergence of numerous snail-breeding sites of in places suitable for human infection (Barbosa et al., 2000; Araújo et al., 2007). Inadequate infrastructures favour the emergence of natural and artificial breeding sites of Biomphalaria snails, making the area a place primed for the transmission of this parasitic disease (Brazilian Ministry of Healthy, 2010). These characteristics are common in peri-urban areas where the population has no access to sewage network systems (Gazzinelli et al., 2006). Our research clearly suggests that re-infection is common along the run-off channel underlining the fact that the infection is related to poverty and low levels of hygiene and sanitation. Most community residents are of low economic class with homes constructed of masonry. In spite of being equipped with closed septic tank systems, they often overflow, while other residue of household sewage is directly released into Invasão do Canal do Guaxinin or streams and ditches around the houses, where snail intermediate hosts breed and become infected. Transmission is seasonal, mainly taking place during the rainy season when the overflow takes the snail-infected contents of the channels to the streets, where people become infected by simple contact with water puddles. In periods of rain, the drainage of rainwater increases, with visible agglomerations of snails, which end up and adapt to the wet backyards where they are regularly found. In contrast, surrounding areas composed of summerhouses and closed condominiums house people of good socio-economic standing who do not frequent the canal region and who are not infected.

Spatial analysis of schistosomiasis, as well as of other diseases, have become frequent because it has become clear that public health and the environment are influenced by spatial patterns of occupation (Barbosa et al., 2005, 2010; Guimarães et al., 2008). Geoprocessing techniques reveal the spatial distribution of health problems, permitting the determination of the local risks for the

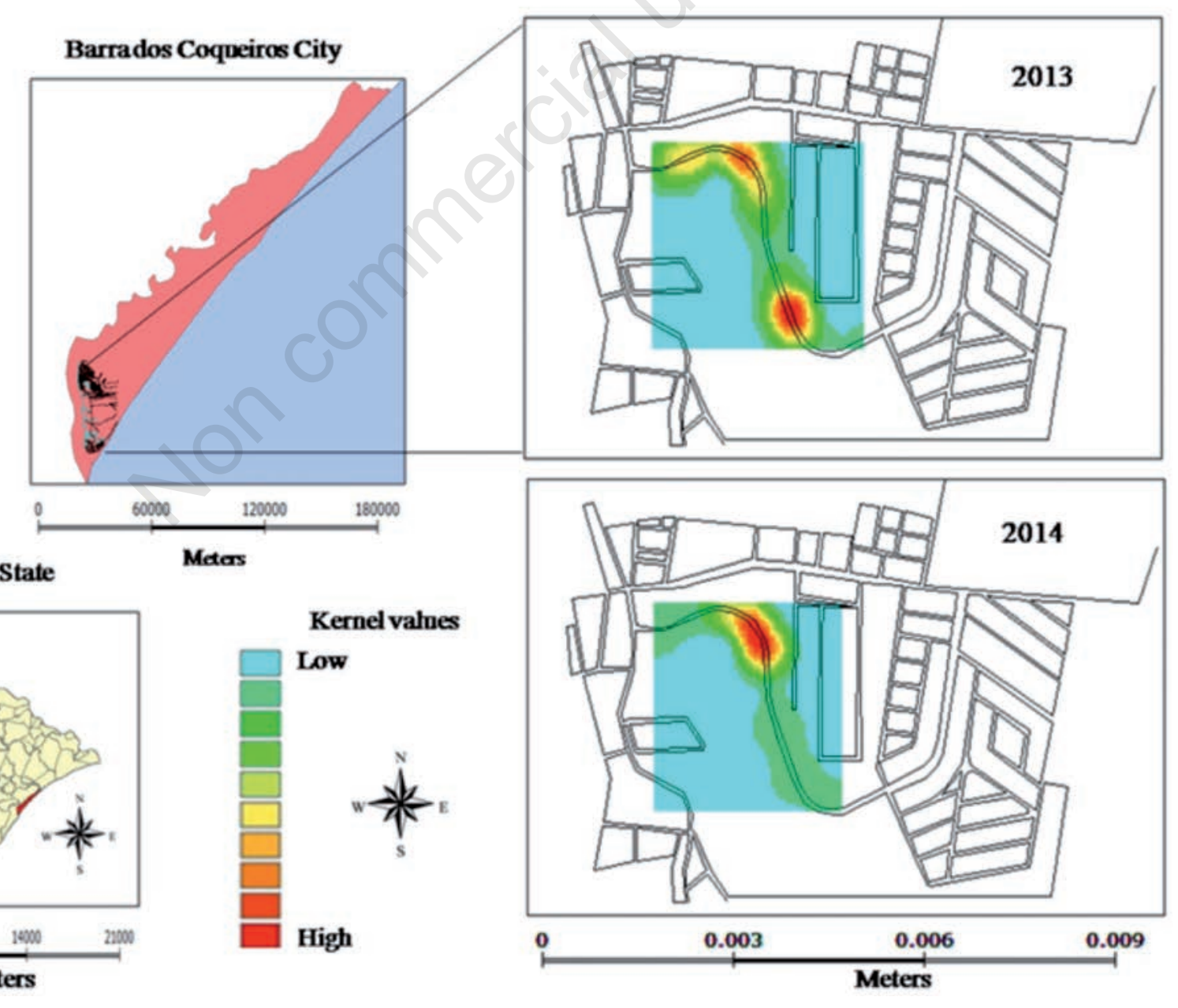

Figure 5. Kernel analysis of human schistosomiasis cases in Invasão do Canal do Guaxinim, Brazil. 
most vulnerable populations (disease occurrence, environmental characteristics and habitat of the intermediate host/vector). Thus, the use of GIS makes it possible to plan, schedule, manage, monitor and evaluate diseases taking the risk of transmission into account (Cromley and McLafferty, 2002). As found in the present study, the distribution was not homogeneous in the community. The cases were concentrated north and south of the channel in 2013, while in 2014 only north of the channel. The expanding community has many water basins and puddles that provide favourable conditions for infection by $S$. mansoni. The northern regions of the community have a higher population density and the spatial analysis reflected this distribution profile in the higher prevalence of infection in this area. Furthermore, the location of the permanent and temporary snail breeding sites may also have contributed to the unequal distribution of schistosomiasis as evidenced by the presence of spatial units with different degrees of risk during the two years of study. It was noted in situ that most georeferenced addresses showed susceptibility factors for the disease; these areas were marked by the presence of dwellings near water bodies containing B. glabrata snails and with a low quality of life with little leisure; these findings corroborate the findings in other studies (Gazzinelli et al., 2006; Barboza et al., 2012).

Spatial analysis shows the importance of knowing the local distribution of a disease under study as it delivers data useful for surveillance and control and facilitates finding new cases through indicating systematic patterns of collection. However, results based on GIS techniques alone do not show the areas of greatest risk of the disease, it is necessary to also collect field data to complete the epidemiological interpretation provided. Together, these data serve as a relevant source of information for improving our understanding of the dynamics of the distribution of infections in the communities studied. They also bring to attention the collective risk suffered by vulnerable populations living under difficult conditions. In this way, spatial analysis supports public health programmes designed to control, prevent and monitor infections, similar to a previous, spatial analysis of schistosomiasis that was conducted in the state of Pernambuco (Barbosa et al., 2010, 2011).

As there is no short- or medium-term global solution to the socio-economic and environmental problems in these areas, specific and efficient measures for schistosomiasis control need to be implemented, taking into account the local epidemiological and ecological features. Thus, chemotherapy should be complemented by measures to minimise snail abundance and prevent, or drastically reduce, individual behaviour (bathing and leisure) increasing the risk of infection, especially among members of the most vulnerable age groups. The present study highlights the importance of local studies designed to improve understanding of the processes leading to infection. Identification and location of the space-time areas where there are different levels of risk for transmission can help guide-planning decisions for health interventions. The presence of the host snail in areas becoming urbanised reflects a concern about the possible occurrence of new breeding sites and possible schistosomiasis foci in these surroundings. It is in this important connection that the municipality of Barra dos Coqueiros is currently considered a priority area for real estate investment and tourism, something that can bring social and economic change to a state that intends to exploit its potential for ecotourism.

\section{Conclusions}

Less densely populated coastal areas with population characterized by underdeveloped social and behavioural conditions are strongly associated with the prevalence of $S$. mansoni infection. Statistical and geospatial analysis contribute to the identification of potential areas of risk of transmission and continued maintenance of this endemic disease. The epidemiologic data observed in this study has shown the importance of basic sanitation, snail control, epidemiological surveillance, promotion of health education along with increased risk awareness, emphasising that these measures should be promoted, as they are needed in addition to chemotherapy. Effective action by PCE staff and training of health professionals can reduce the local high prevalence of $S$. mansoni.

\section{References}

Araújo KC, Resendes AP, Souza-Santos R, Silveira Junior JC, Barbosa CS, 2007. Spatial analysis of Biomphalaria glabrata foci and human cases of mansoni schistosomiasis in Porto de Galinhas, Pernambuco State, Brazil, in the year 2000. Cad Saude Publica 23:409-17.

Barbetta PA, 2002. Estatística Aplicada às ciências sociais. Universidade Federal de Santa Catarina, Florianópolis, Brazil.

Barbosa CS, Araújo KC, Sevilla MAA, Melo F, Gomes ECS, Souza-Santos R, 2010. Currente epidemiological status of schistosomiasis in the state of Pernambuco, Brazil. Mem Inst Oswaldo Cruz 4:549-54.

Barbosa CS, Araújo KCG, Favre T, Pieri O, 2005. Spacial distribution of schistosoma mansoni foci in Itamaracá Island, Pernambuco, Brazil. Mem Inst Oswaldo Cruz 99:79-83.

Barbosa CS, Barbosa VS, Nascimento WC, Pieri OS, Araujo KCGM, 2014. Study of the snail intermediate hosts for Schistosoma mansoni on Itamaracá Island in northeast Brazil: spatial displacement of Biomphalaria glabrata by Biomphalaria straminea. Geospat Health 8:345-51.

Barbosa CS, Favre TC, Wanderley TN, Callou AC, Pieri OS, 2006. Assessment of schistosomiasis, through school surveys, in the Forest Zone of Pernambuco, Brazil. Mem Inst Oswaldo Cruz 101:55-62.

Barbosa CS, Leal-Neto OB, Gomes ECS, Araújo KCGM, Domingues ALC, 2011. The endemisation of schistosomiasis in Porto de Galinhas, Pernambuco, Brazil, 10 years after the first epidemic outbreak. Mem Inst Oswaldo Cruz 7:878-83.

Barbosa CS, Pieri OS, Barbosa FS, 2000. Ecoepidemiologia da esquistossomose urbana na ilha de Itamaracá, Estado de Pernambuco. Rev Saude Publica 34:337-41.

Barboza DM, Zhang C, Santos NC, Silva MMBL, Rollemberg CVV, Amorim FJR, Ueta MT, Melo CM, Almeida JAP, Jeraldo VLS, Jesus AR, 2012. Biomphalaria species distribution and its effect on human Schistosoma mansoni infection in an irrigated area used for rice cultivation in northeast Brazil. Geospat Health 6:103-9.

Brazilian Ministry of Healthy, 2010. [Guia de Vigilância Epidemiológica]. Brazilian Ministry of Healthy, Brasília, Brazil.

Brazilian Ministry of Healthy, 2013. [Programa de Controle da Esquistossomose]. [Programme in Brazilian]. Brazilian Ministry of Healthy, Brasília, Brazil.

Carvalho MS, Souza-Santos R, 2005. Análise de dados espaciais 
em saúde pública: métodos, problemas, perspectivas. Cad Saude Publica 21:361-78.

Chitsulo L, Engels D, Montresor A, Savioli L, 2000. The global status of schistosomiasis and its control. Acta Trop 77:41-51.

Clennon JA, King CH, Muchiri EM, Kitron U, 2007. Hydrological modelling of snail dispersal patterns in Msambweni, Kenya and potential resurgence of Schistosoma haematobium transmission. Parasitology 5:683-93.

Cromley EK, McLafferty SL, 2002. GIS and public health. Guilford Press, New York, NY, USA.

DATASUS, 2015. Departamento de Informática do SUS. Available from: http://www2.datasus.gov.br/

Deslandes N, 1951. Técnicas de dissecção e exame de planorbídeos. Rev Serv Espec Saúde Pública 4:371-82.

Enk MJ, Amaral GL, Silva MF, Silveira-Lemos D, TeixeiraCarvalho A, Martins-Filho OA, Correa-Oliveira R, Gazinnelli G, Coelho PM, Massara CL, 2010. Rural tourism: a risk factor for schistosomiasis transmission in Brazil. Mem Inst Oswaldo Cruz 105:537-40.

Gazzinelli A, Velasquez-Melendez G, Crawford SB, Loverde PT, Corrêa-Oliveira R, Kloss H, 2006. Socioeconomic determinants of schistosomiasis in a rural area in Brazil. Acta Trop 99:260-71.

Gryseels B, 1994. Human resistance to Schistosoma infections: age or experience? Parasitol Today 10:380-4.

Guimarães R, Freitas C, Dutra L, Moura A, Amaral R, Drummond S, Scholte R, Carvalho O, 2008. Schistosomiasis risk estimation in Minas Gerais state, Brazil, usingenvironmental data and GIS techniques. Acta Trop 108:234-41.

Hofmann-Wellenhof B, Lichtenegger H, Collins J, 1997. GPS theory and practice. Springer-Verlag, Berlin, Germany.

Hotez PJ, Bethony JM, Diemert DJ, Pearson M, Loukas A, 2010. Developing vaccines to combat hookworm infection and intestinal schistosomiasis. Nat Rev Microbiol 8:814-26.

IBGE, 2015. IBGE Cidades. Available from: http://www. cidades.ibge.gov.br/xtras/perfil.php?lang=\&codmun $=280060$

Katz N, Chaves A, Pelegrino J, 1972. A simple device for quantitative stool thick-smear technique in schistosomiasis mansoni. Rev Inst Med Trop São Paulo 14:373.
Massara CL, Amaral G, Caldeira R, Drummond S, Enk M, Carvalho O, 2008. Esquistossomose em área de ecoturismo do Estado de Minas Gerais. Cad Saude Publica 24:1709-12.

Olivier L, Schneiderman M, 1956. A method for estimating the density of aquatic snail populations. Exper Parasitol 5:109-17.

Rollemberg CVV, Santos CMB, Souza AMB, Silva AM, Almeida JAP, Almeida RP, Jesus AR, 2011. Aspectos epidemiológicos e distribuição geográfica da esquistossomose e geo-helmintos, no Estado de Sergipe, de acordo com os dados do Programa de Controle da Esquistossomose. Rev Soc Bras Med Trop 44:91-6.

Santos AD, Lima ACR, Santos MB, Alves JAB, Goes MAO, Nunes MAP, Sá SL, Araújo KC, 2016. Spatial analysis for the identification of risk areas for schistosomiasis mansoni in the State of Sergipe, Brazil, 2005-2014. Rev Soc Bras Med Trop 49:608-15.

Sarvel AK, Oliveira AA, Silva AR, Lima ACL, Katz N, 2011. Evaluation of a 25-year-program for the control of Schistosomiasis Mansoni in an endemic area in Brazil. PLoS Negl Trop Dis 5:1-6.

Scholte RGC, Carvalho OS, Malone JB, Utzinger J, Vounatsou P, 2012. Spatial distribution of Biomphalaria spp., the intermediate host snails of Schistoso mamansoni, in Brasil. Geospat Health 6:95-101.

Scholte RGC, Gosoniu L, Malone JB, Chammartin F, Utzinger J, Vounatsou P, 2014. Predictive risk mapping of schistosomiasis in Brazil using Bayesian geostatistical models. Acta Trop 132:57-63.

Souza CP, Lima LC, 1990. Moluscos de interesse parasitológico do Brasil. Fundação Oswaldo Cruz, Centro de Pesquisas René Rachou, Belo Horizonte, Brazil.

Sturrock RF, 1993. The intermediate hosts and host-parasite relationships. In: Jordan P, Webbe G, Sturrock RF, eds. Human schistosomiasis. CAB International, Wallingford, UK. pp. 33-85.

WHO, 2014. Schistosomiasis. Available from: http://www.who. int/mediacentre/factsheets/fs $115 / \mathrm{en} /$

Yang GJ, Vounatsou P, Zhou XN, Utzinger J, Tanner M, 2005. A review of geographic information system and remote sensing with applications to the epidemiology and control of schistosomiasis in China. Acta Trop 96:117-29. 